\title{
An Electromagnetically Actuated Fiber Optic Switch Using Magnetized Ferromagnetic Materials
}

\author{
Praveen Pandojirao-S, Naresh Dhaubanjar, Pratibha C. Phuyal, Mu Chiao", J.-C. Chiao \\ Dept. of Electrical Engineering, The Univ. of Texas at Arlington, Arlington, TX USA 76019 \\ *Department of Mechanical Engineering, University of British Columbia, Canada.
}

\begin{abstract}
This paper presents the design, fabrication and testing of a fiber optic switch actuated electromagnetically. The ferromagnetic gel coated optical fiber is actuated using external electromagnetic fields. The ferromagnetic gel consists of ferromagnetic powders dispersed in epoxy. The fabrication utilizes a simple cost-effective coating setup. A direct fiberto-fiber alignment eliminates the need for complementary optical parts and the displacement of fiber switches the laser coupling. The magnetic characteristics of magnetized ferromagnetic materials are performed using alternating gradient magnetometer and the magnetic hysteresis curves are measured for different ferromagnetic materials including iron, cobalt, and nickel. Optical fiber switches with various fiber lengths are actuated and their static and dynamic responses for the same volume of ferromagnetic gel are summarized. The highest displacement is $1.345 \mathrm{~mm}$ with an input current of $260 \mathrm{~mA}$. In this paper, the performance of fiber switches with various coating materials is presented.
\end{abstract}

Keywords: Optical switch, MEMS, MOEMS, magnetized, magneto optical

\section{INTRODUCTION}

Applications of fiber optic switches include optical fiber communications, industrial fiber-optic sensing, biomedical imaging and sensing, and photonic signal processing. All-optical switches enable routing of data without the need for optical to electrical conversion. Fiber optical switches are also widely used for optical amplitude modulator [1-3], and medical imaging [4-8]. Fiber optical devices have been developed with piezoelectric [9], electrostatic [10, 11], thermal $[12,13]$, and electromagnetic [14-16] actuation. Thermal devices have higher power consumption and piezoelectric and electrostatic devices require high voltage input. Micromechanical devices using electromagnetic actuation have shown low power consumption and high displacement [14-16].

This paper reports the design and development of a low-cost, fiber optic switch with simple fabrication process, low power consumption, and high precision. With different magnetized ferromagnetic coatings, such as nickel, cobalt, and iron, and external electromagnetic actuation, our fiber optic switches have been characterized statically and dynamically. Silica optical fibers of lengths of $4.2 \mathrm{~cm}, 5.2 \mathrm{~cm}, 6.2 \mathrm{~cm}$ and $7.2 \mathrm{~cm}$ have been characterized. The goals of this study are to verify the characteristics of fiber optic switches and designs based on different magnetized ferromagnetic materials.

\section{FABRICATION OF OPTICAL SWITCH}

In our design, the ferromagnetic material is mixed with epoxy and coated using a delicate brush. Ferromagnetic gel consists of $70 \%$ by weight of epoxy and $30 \%$ by weight of ferromagnetic powder. The optical fiber coated with gel on its cladding is shown in Fig 1. The ferromagnetic gel is cured at the room temperature for 20 minutes. The coated fiber is then kept under a permanent magnet for one week to magnetize the ferromagnetic gel. A clean paper separates the physical contact of the permanent magnet from the coating. Ferromagnetic materials of nickel, cobalt, and iron powders and various actuation fiber lengths of $7.2 \mathrm{~cm}, 6.2 \mathrm{~cm}, 5.2 \mathrm{~cm}$, and $4.2 \mathrm{~cm}$ are used to investigate the maximum deflections and resonant frequencies.

\section{WORKING PRINCIPLE AND EXPERIMENTAL SETUP}

The experimental setup of the fiber optic switch is shown in Fig. 2. It consists of an external electromagnet, a singlemode optical fiber coated with magnetic gel, a HeNe laser, an objective lens, and a position sensitive detector (PSD) [17]. The PSD is used to detect deflection of the fiber under the influence of magnetic fields. The distance between electromagnet and the magnetic coating of the fiber is kept at $3 \mathrm{~mm}$ for all the experiments. The HeNe laser at a

MEMS/MOEMS Technologies and Applications III, edited by

Jung-Chih Chiao, Xuyuan Chen, Zhaoying Zhou, Xinxin Li,

Proc. of SPIE Vol. 6836, 683616, (2007) · 0277-786X/07/\$18 · doi: 10.1117/12.758063

Proc. of SPIE Vol. 6836 683616-1 
wavelength of $632.8 \mathrm{~nm}$ and an optical power of $20 \mathrm{~mW}$ is focused onto an objective lens with a focal length of $0.5 \mathrm{~mm}$. The objective lens focuses the laser beam to the optical fiber as shown in Fig. 3. For static analysis, a D.C. power source is used for the electromagnet. For the dynamic analysis, an A.C. sinusoidal input is applied to the electromagnet, which has a bandwidth of $60 \mathrm{~Hz}$ and a resistance of 30 ' $\Omega$. The magnetic field strength of the electromagnet from magnetic core is measured experimentally by a Gaussmeter [18].

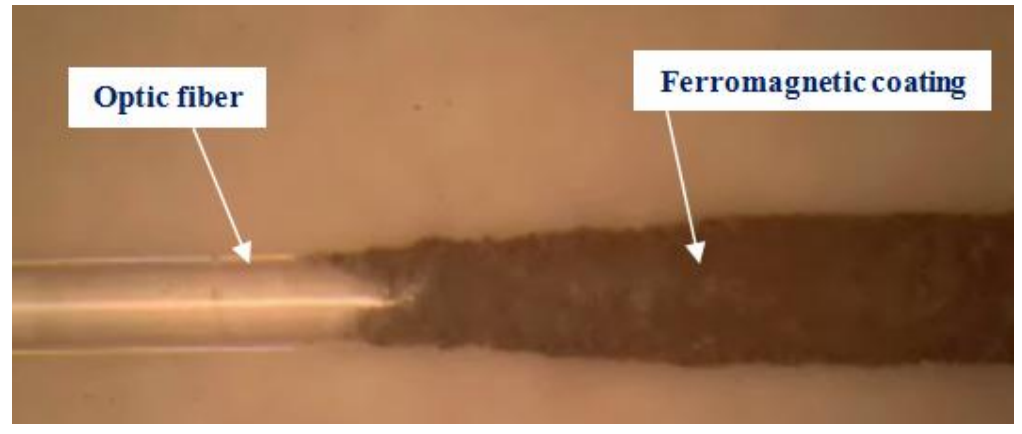

Figure 1 Optic fiber with ferromagnetic coating.
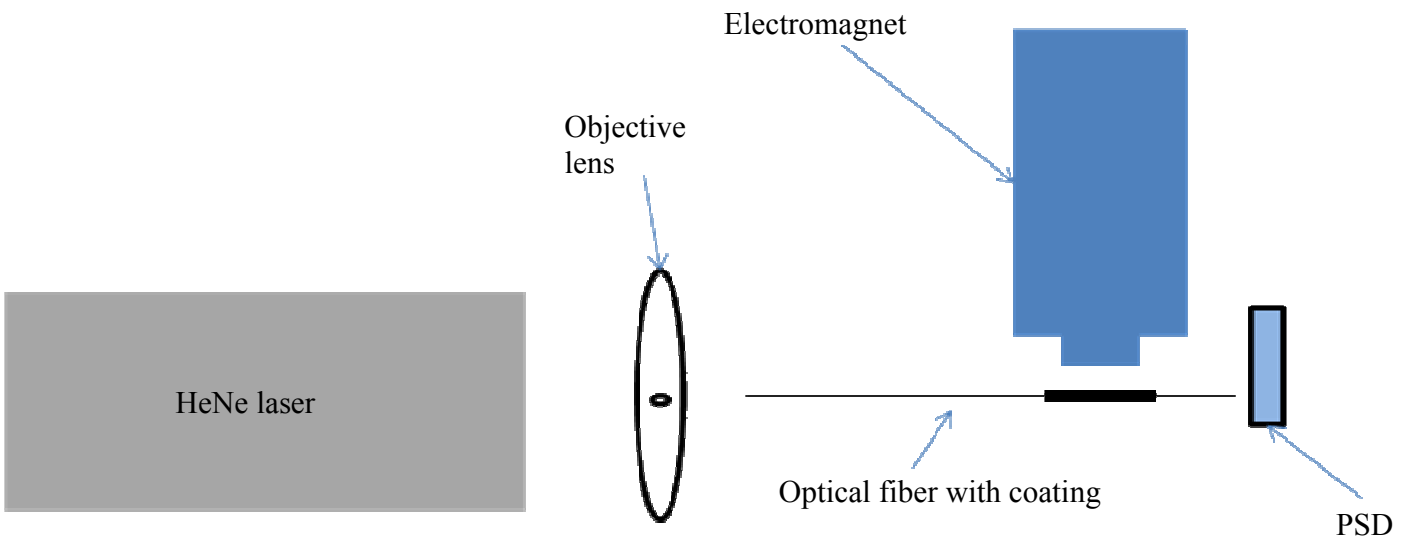

Figure 2 Experimental setup of the fiber optic switch.

\section{DISPLACEMENT, RESONANCE AND MAGNETIC PROPERTIES}

The displacement due to the electromagnetic field can be calculated using the relation [19, 20]:

$$
d=\mu_{o} M V \frac{d H_{o}}{d z}\left(\frac{b^{3}}{3 E I}+\frac{a^{3}}{3 E I}\right)
$$

where $\mu_{o}$ is the magnetic permeability, $M$ the magnetization vector, $V$ is the volume of the ferromagnetic gel, $\frac{d H_{o}}{d z}$ is the gradient of the magnetic field, $E$ is the Young's modulus, $I$ is the moment of inertia, $b$ and $a$ are the distances from the gel coating to the free end and fixed end of the optic fiber as shown in Fig. 4. The resonant frequency of the above setup can be calculated [21] as

$$
f=\frac{1}{2 \pi} \sqrt{\frac{3 E I}{l^{3}\left(M_{g}+0.23 m_{f}\right)}}
$$


where $l$ is the actuating length of the fiber (equal to $a+b), M_{g}$ is the mass of the ferromagnetic gel, and $m_{f}$ is the mass of the fiber. Ferromagnetic materials exhibit hysteresis. The magnetic properties of the ferromagnetic materials are found

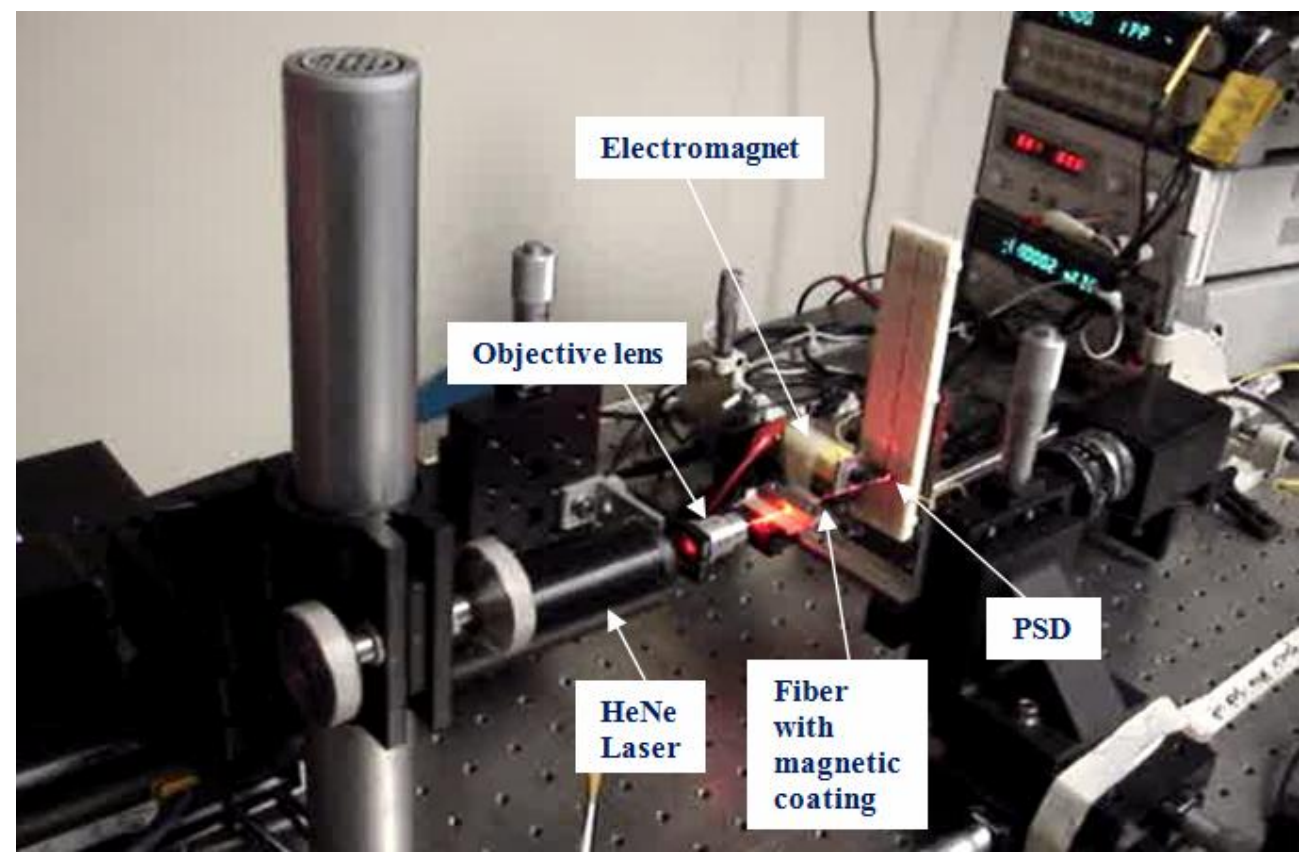

Figure 3 A photo of the experimental setup of the fiber optic switch.

using alternating gradient magnetometer (AGM). To analyze the magnetic properties, a rectangular strip of the ferromagnetic gel coating is magnetized by using a permanent magnet first. This sample is then loaded into the AGM and analyzed. The coercivity field $H_{c}$, remnant flux $M_{r}$, saturation flux $M_{s}$ and other key parameters for various magnetized ferromagnetic materials nickel, cobalt, and iron are shown in Fig. 5. For nickel sample, a planar film of 2 $\mathrm{mm}$ by $2.5 \mathrm{~mm}$ in area and $0.01 \mathrm{~mm}$ in thickness is used. The saturation magnetic volume density of the magnetic gel is found to be $90.9 \mathrm{KA} / \mathrm{m}$. In the case of iron, the saturation magnetic volume density is $194.1 \mathrm{KA} / \mathrm{m}$ for planar films of a size of $2 \mathrm{~mm}$ by $2 \mathrm{~mm}$ and a thickness of $0.01 \mathrm{~mm}$. For cobalt, a planar $0.01 \mathrm{~mm}$ thick film of $3 \mathrm{~mm}$ by $2.5 \mathrm{~mm}$ in area was used and the saturation magnetic volume density of the magnetic gel is found to be $31.5 \mathrm{KA} / \mathrm{m}$.

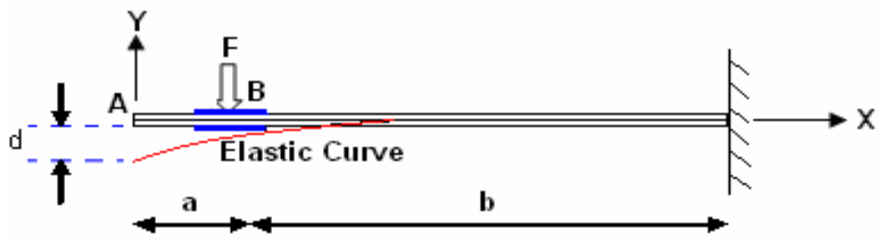

Figure 4 Displacement and the configuration of the fiber.

\section{STATIC ANALYSIS}

For the static analysis, a DC voltage is applied directly onto the electromagnet. A current meter connected in series is used to monitor the current flow. An oscilloscope is connected to monitor the voltage across the PSD as shown in Fig. 6. Static analysis is performed using a fiber with a single layer coating approximately $40 \mu \mathrm{m}$ in thickness. The spring constant [18] for a $4.2 \mathrm{~cm}$ length fiber is found to be $\mathrm{K}=35.12 \times 10^{-3} \mathrm{~N} / \mathrm{m}$. Fig. 7a shows the static displacements of 4.2 $\mathrm{cm}$ silica optical fiber using magnetized nickel, cobalt and iron gel coating. The cobalt gel produces higher actuation displacement than other two gels. Similarly, for the $5.2 \mathrm{~cm}$ length fiber, the spring constant is found to be $18.50 \times 10^{-3}$ $\mathrm{N} / \mathrm{m}$. The experimental results of static displacement are shown in Fig. $7 \mathrm{~b}$ for magnetized nickel, iron and cobalt. In this case, cobalt has higher deflection than iron and nickel at a given input electromagnetic field. The spring constant for a 
$6.2 \mathrm{~cm}$ long fiber is $10.92 \times 10^{-3} \mathrm{~N} / \mathrm{m}$. Since the spring constant is much lower than those of $4.2 \mathrm{~cm}$ and $5.2 \mathrm{~cm}$ cases, the deflection is higher as shown in Fig. 7c. For a fiber length of $7.2 \mathrm{~cm}$, the spring constant is $6.9704 \times 10^{-3} \mathrm{~N} / \mathrm{m}$. The deflection is shown in Fig. 7d. The fibers with various magnetic gels are actuated at different currents to be tested in the similar displacement ranges within the PSD detection area. With the similar currents used for the $4.2 \mathrm{~cm}$ or $5.2 \mathrm{~cm}$ fiber lengths, the laser output reached outside the PSD detectable ranges. The results of static analysis with magnetized nickel, cobalt and iron are tabulated and compared in Table 1. Magnetized cobalt coating fibers have generally higher deflection than magnetized nickel and iron fiber given the same actuating fiber length.

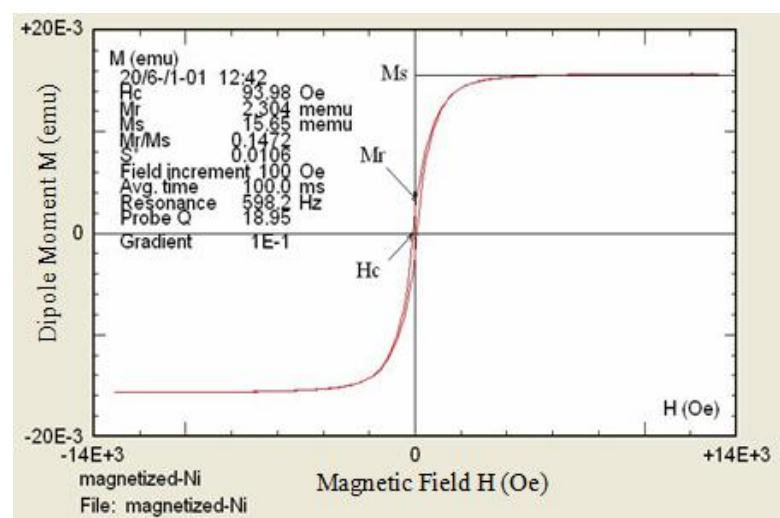

(a)

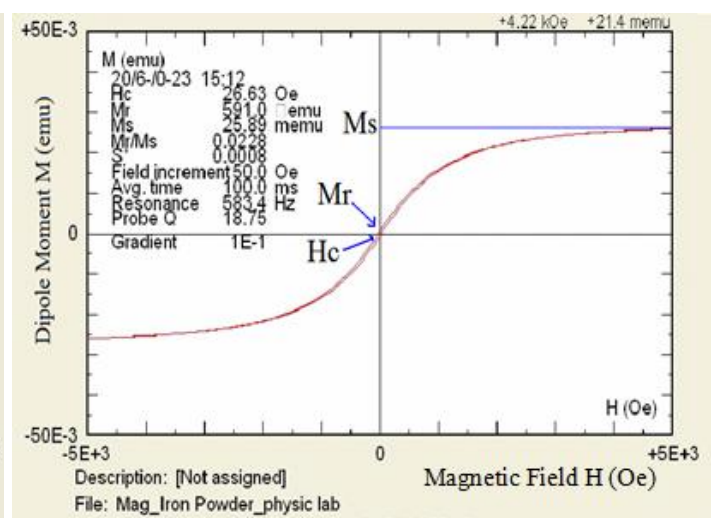

(b)

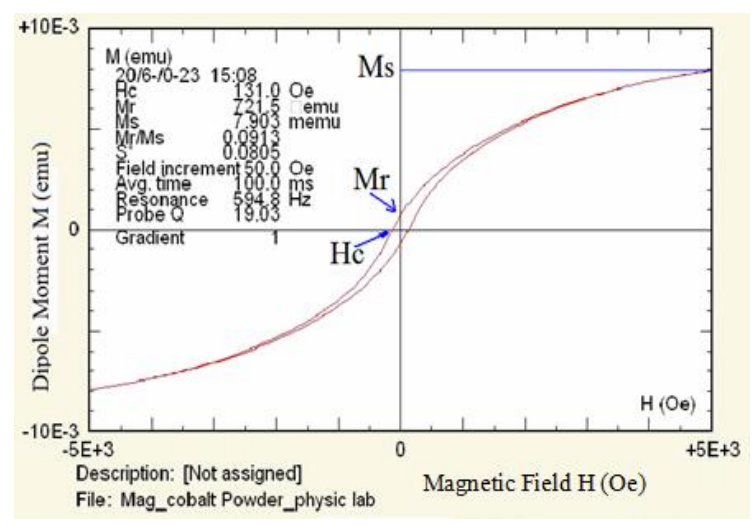

(c)

Figure 5 Hysteresis for magnetized ferromagnetic materials (a) nickel (b) iron and (c) cobalt.

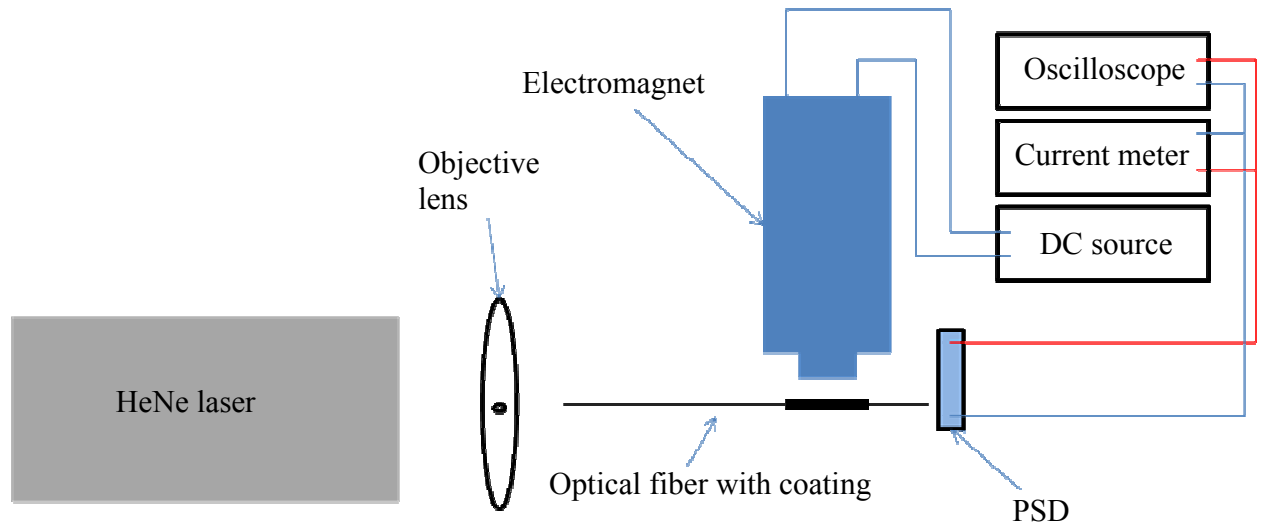

Figure 6 Experimental set up for the static analysis. 


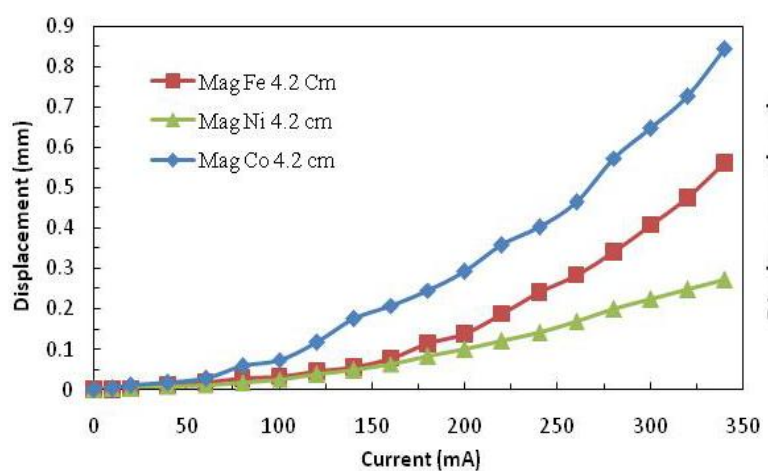

(a)

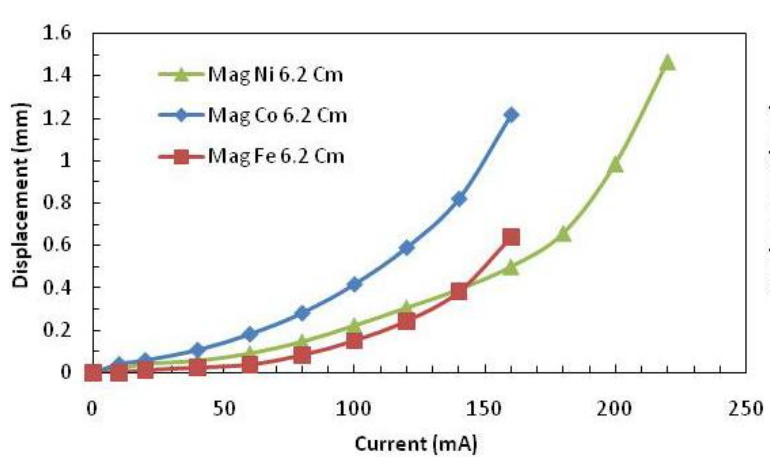

(c)

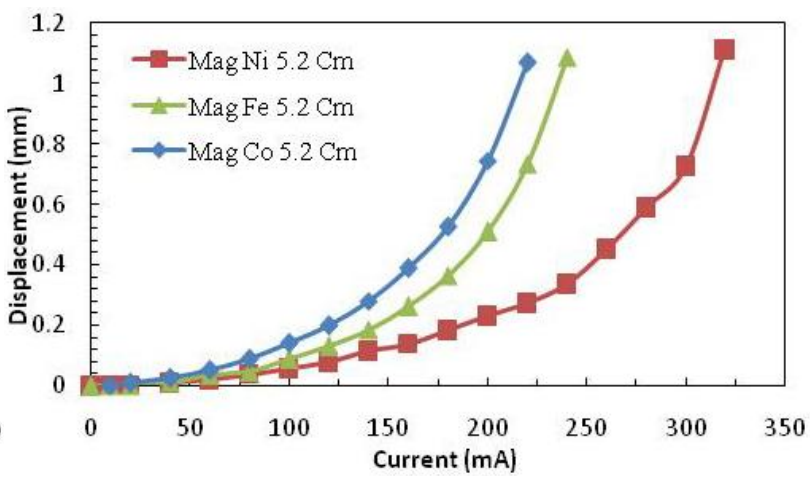

(b)

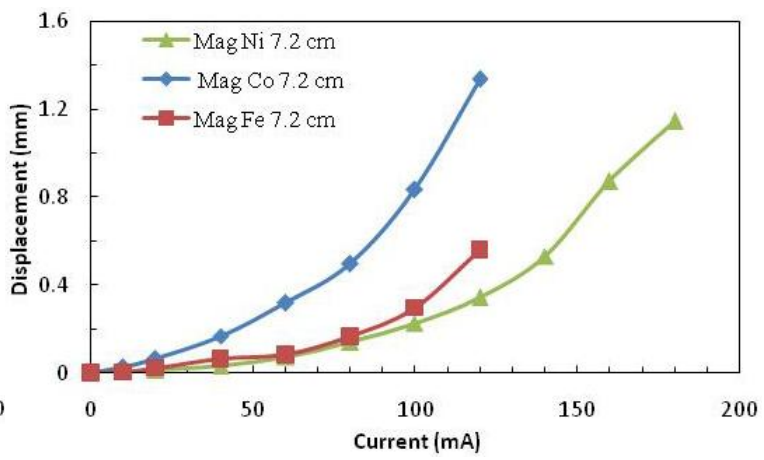

(d)

Figure 7 Static displacements of silica optical fibers with a length of (a) $4.2 \mathrm{~cm}$ (b) $5.2 \mathrm{~cm}$ (c) $6.2 \mathrm{~cm}$ and (d) $7.2 \mathrm{~cm}$.

Table 1 Comparison of static displacements for magnetized materials on various lengths of fibers.

\begin{tabular}{|c|c|c|c|c|}
\hline $\begin{array}{c}\text { Length } \\
(\mathrm{cm})\end{array}$ & $\begin{array}{c}\text { Current } \\
(\mathrm{mA})\end{array}$ & $\begin{array}{c}\text { Displacements } \\
\text { using iron } \\
\text { powder } \\
(\mathrm{mm})\end{array}$ & $\begin{array}{c}\text { Displacements } \\
\text { using cobalt } \\
\text { powder } \\
(\mathrm{mm})\end{array}$ & $\begin{array}{c}\text { Displacements } \\
\text { using nickel } \\
\text { powder } \\
(\mathrm{mm})\end{array}$ \\
\hline 4.2 & 340 & 0.5616 & 0.8424 & 0.2719 \\
\hline 5.2 & 220 & 0.7342 & 1.345 & 0.2726 \\
\hline 6.2 & 160 & 0.6393 & 1.212 & 0.4991 \\
\hline 7.2 & 120 & 0.5616 & 1.337 & 0.3418 \\
\hline
\end{tabular}

\section{DYNAMIC ANALYSIS}

To perform dynamic analysis, a function generator and an oscilloscope are used to produce the actuation waveforms as shown in Fig. 8. At resonance, the frequency of the output signals from the PSD is approximately double of the frequency of the driving signals as shown in Fig. 9. For example, with a cobalt-coated fiber length of $5.2 \mathrm{~cm}$, an input frequency of $12.8 \mathrm{~Hz}$ produces a scanning frequency of $25.64 \mathrm{~Hz}$. This is consistent for all the magnetized materials and for all the lengths of fiber used.

Dynamic analysis is performed for $4.2 \mathrm{~cm}, 5.2 \mathrm{~cm}, 6.2 \mathrm{~cm}$, and $7.2 \mathrm{~cm}$ length fibers. The resulting resonant frequencies are summarized in Table 2. Fig. 10 shows the dynamic displacements and resonant frequencies of the magnetized nickel, 
iron and cobalt coated fibers. With the input frequency set at resonance, maximum actuation of the fibers with magnetized nickel, cobalt and iron are performed and the results are tabulated in Table 3. It is seen that magnetized cobalt has the highest actuation compared to the magnetized nickel and iron counterparts.

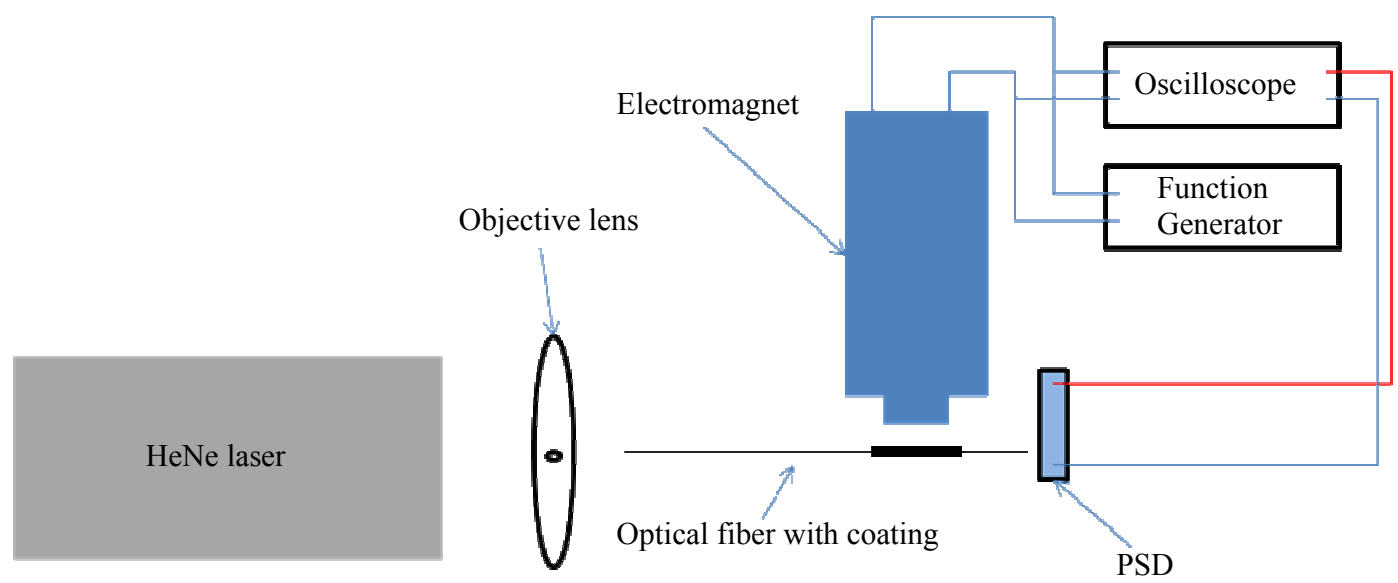

Figure 8 Experimental setup for dynamic analysis.

Table 2 Comparison of resonant frequencies of magnetized ferromagnetic materials

\begin{tabular}{|c|c|c|c|}
\hline \multirow{3}{*}{$\begin{array}{c}\text { Length } \\
(\mathrm{cm})\end{array}$} & $\begin{array}{c}\text { Magnetized nickel } \\
\text { coating }\end{array}$ & $\begin{array}{c}\text { Magnetized cobalt } \\
\text { coating }\end{array}$ & $\begin{array}{c}\text { Magnetized iron } \\
\text { coating }\end{array}$ \\
\cline { 2 - 4 } & $\begin{array}{c}\text { resonental } \\
\text { frequency } \\
(\mathrm{Hz})\end{array}$ & $\begin{array}{c}\text { Experimental } \\
\text { resonant } \\
\text { frequency } \\
(\mathrm{Hz})\end{array}$ & $\begin{array}{c}\text { Experimental } \\
\text { resonant } \\
\text { frequency } \\
(\mathrm{Hz})\end{array}$ \\
\hline 4.2 & 37.40 & 37.4 & 40.23 \\
\hline 5.2 & 25.00 & 25.00 & 26.32 \\
\hline 6.2 & 17.56 & 17.54 & 17.86 \\
\hline 7.2 & 12.82 & 12.82 & 12.20 \\
\hline
\end{tabular}

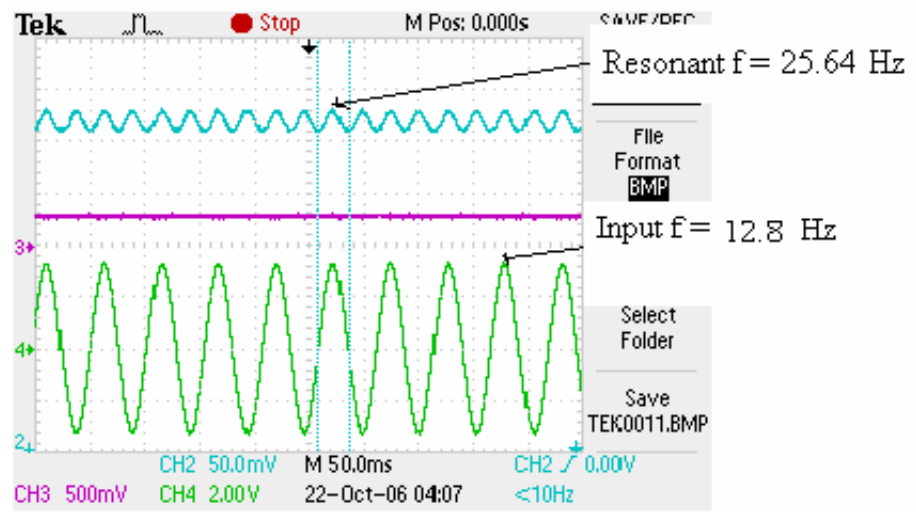

Figure 9 Electromagnet driving waveforms compared to the PSD output waveforms in the case of magnetized cobalt coating and a fiber length of $5.2 \mathrm{~cm}$ 


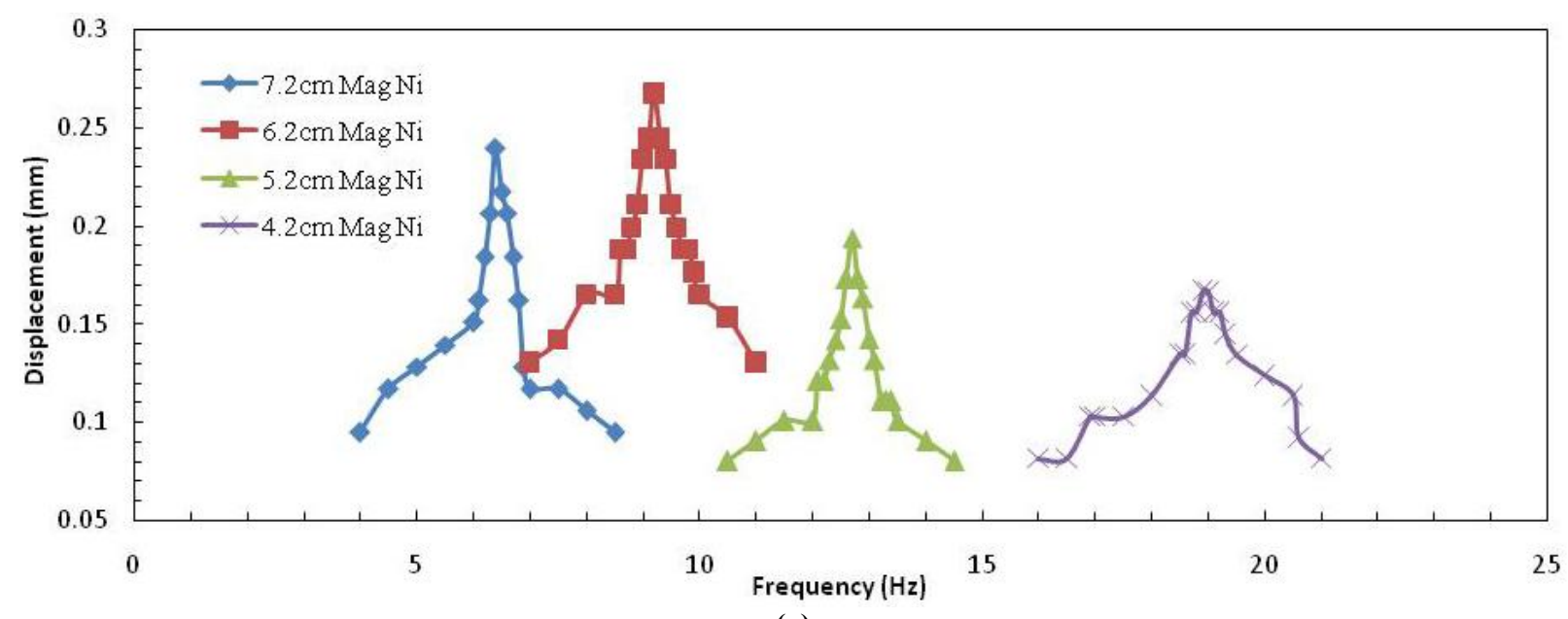

(a)

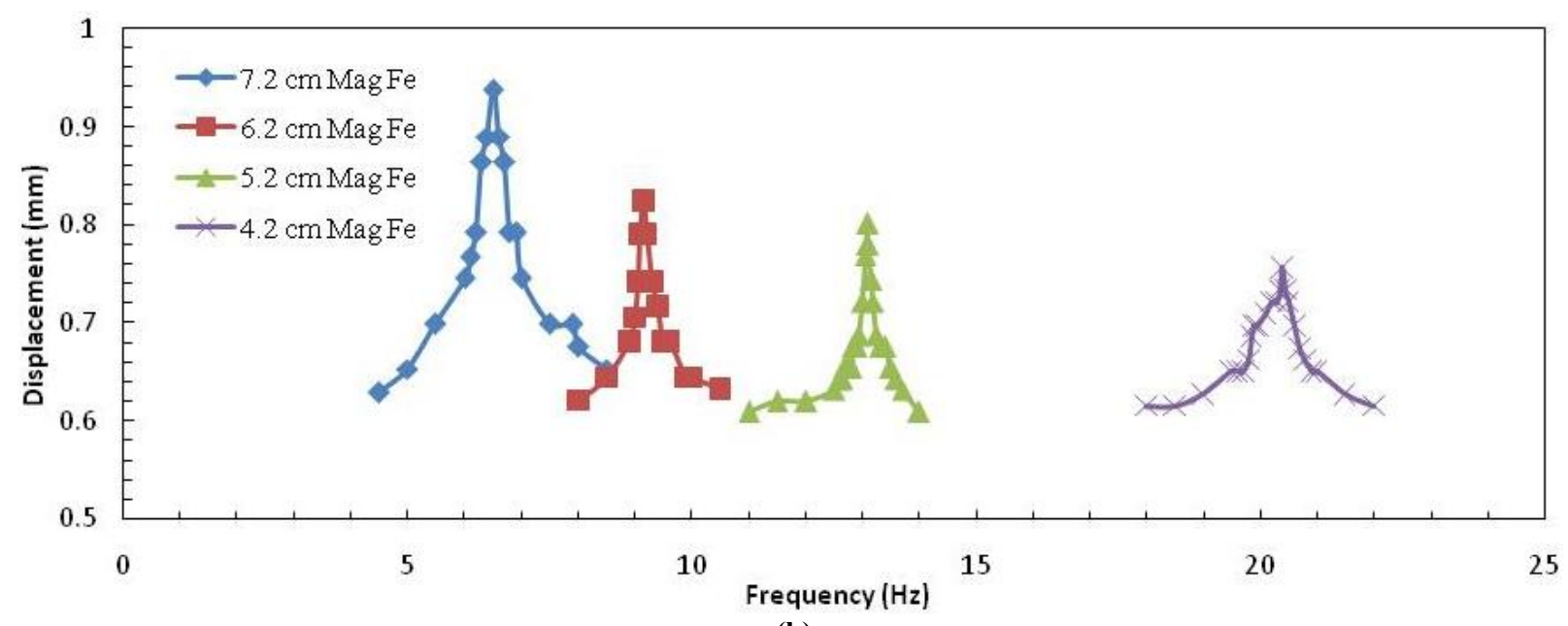

(b)

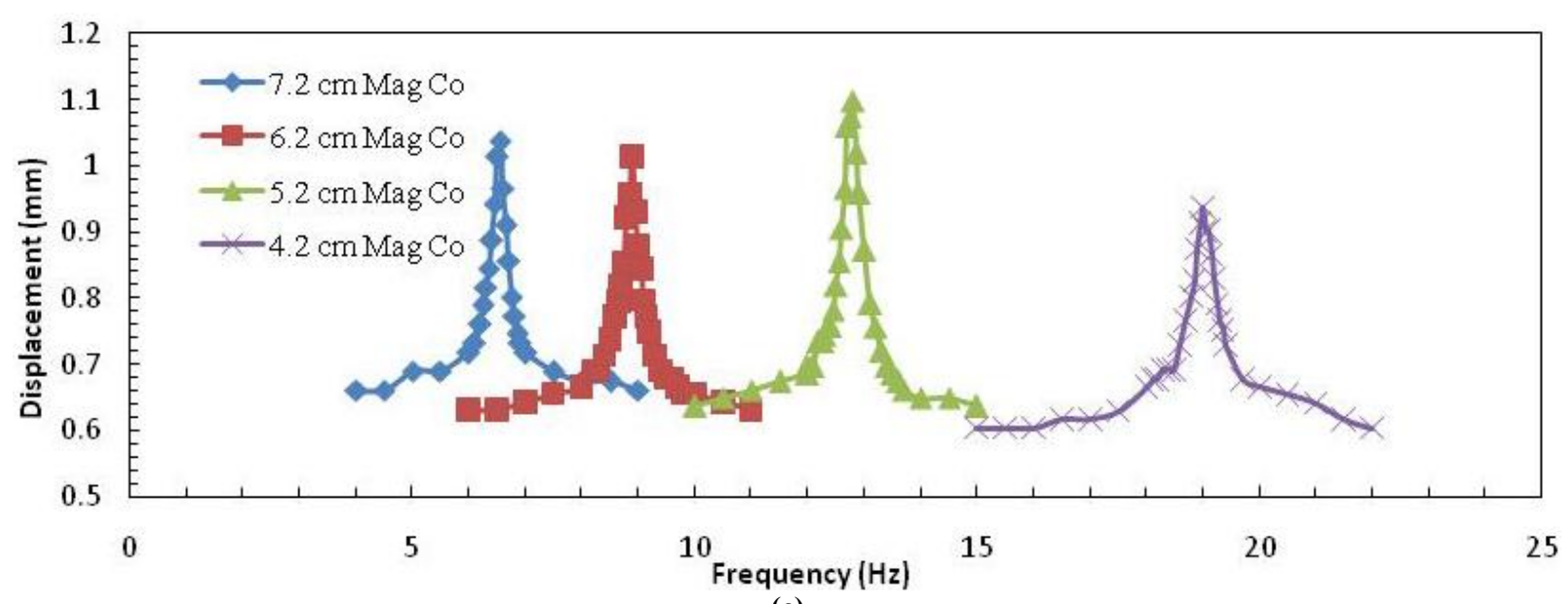

(c)

Figure 10 Dynamic analysis of magnetized (a) nickel, (b) iron, and (c) cobalt coated fibers with various lengths. 
Table 3 Comparison of maximum actuation at resonant frequencies.

\begin{tabular}{|c|c|c|c|}
\hline $\begin{array}{c}\text { Length } \\
(\mathrm{cm})\end{array}$ & $\begin{array}{c}\text { Displacements using iron } \\
\text { powder }(\mathrm{mm})\end{array}$ & $\begin{array}{c}\text { Displacements using cobalt } \\
\text { powder }(\mathrm{mm})\end{array}$ & $\begin{array}{c}\text { Displacements using nickel } \\
\text { powder }(\mathrm{mm})\end{array}$ \\
\hline 4.2 & 0.757 & 0.938 & 0.166 \\
\hline 5.2 & 0.801 & 1.098 & 0.343 \\
\hline 6.2 & 0.825 & 1.014 & 0.267 \\
\hline 7.2 & 0.938 & 1.038 & 0.234 \\
\hline
\end{tabular}

\section{CONCLUSIONS}

Magnetic characteristics of magnetized ferromagnetic materials have been performed. The magnetic hysteresis curve and the other magnetic properties are found for different magnetized ferromagnetic materials. The magnetized ferromagnetic materials have different magnetic properties than the non-magnetized materials. Among the magnetized materials, cobalt has the highest displacements compared to nickel and iron. Fiber length of $5.2 \mathrm{~cm}$ produces the highest displacements $(1.345 \mathrm{~mm})$ with an input current of $260 \mathrm{~mA}$. For a given volume of the ferromagnetic gel coating, the $7.2 \mathrm{~cm}$ length fiber has the highest displacement of $1.338 \mathrm{~mm}$ with an input current of $120 \mathrm{~mA}$ due to the low Young's modulus. Among the magnetized materials, cobalt has the highest displacements compared to nickel and iron. Optic fibers with magnetized ferromagnetic gel coating can be used to build an optical switch.

\section{REFERENCES}

[1] S. P. Fang, and H. F. Taylor, "High-performance single-mode fiber-optic switch", Optics Letters, 19:1204-1206. 1994.

[2] Shi-Sheng Lee, Ed Motamedi, and Ming C. Wu, "Surface-micromachined free-Space fiber optic switches with integrated microactuators for optical fiber communication systems", Transconductor'97 1997 International Conference on Solid-State Sensors and Actuators, Chicago, June 16-19. 1997.

[3] I. R. Matias, M. Lopez-Amo, F. Montero, C. Fernandez-Valdivielso, F. J. Arregui, and C. Bariain, "Low-cost optical amplitude modulator based on a tapered single-mode optical fiber", Applied Optics, Vol. 40, No.2. January 2001.

[4] S.A. Boppart, B.E. Bouma, C. Pitris, G.J. Tearney, and J.G. Fujimoto, "Forward-imaging instruments for optical coherence tomography", Optics Letters, Vol. 22, No. 21. November 1997.

[5] R. Nelson, J.R. Krone, and O.Jansson, "Surface plasmon resonance biomolecular interaction analysis mass spectrometry", Anal Chem, 69(21): 4369-74. Nov 1997.

[6] M. Sedlar, V. Matejec, and I. Paulicka, "Optical fiber magnetic field sensors using ceramic magnetostrictive jackets", Sensors and Actuators, 84: 297-302. 2000.

[7] R.S. Popovic, J.A. Flanagan, and P.A. Besse, "The future of magnetic sensors", Sensor and Actuators, A56:3955. 1996.

[8] F. Keplinger, S. Kvasnica, A. Jachimowicz, F. Kohl, J. Steurer, and H. Hauser, "Lorentz force based magnetic field sensor with optical readout", Sensors and Actuators, A 110:112-118. 2004.

[9] S.P. Fang and H.F. Taylor. "High-performance single-mode fiber-optic switch" Optics Letters, Vol. 19, No. 15. 1994.

[10] S. Lee, E. Motamedi, and M.C. Wu, "Surface-micromachined free-space fiber optic switches with integrated microactuators for optical fiber communication systems", Transconductor'97 1997 International Conference on Solid-State Sensors and Actuators, Chicago, June 16-19. 1997.

[11] M. Herding, F. Richardt, and P. Woias, "A novel approach to low-cost optical fiber switches", IEEE/LEOS International Conference on Optical MEMS, Aug 18-21, 2003.

[12] M. Hoffmann, P. Kopka, E. Voges, "Bistable micromechanical fiber-optic switches on silicon with thermal actuators", Sensors and Actuators, 78:28-35. 1999.

[13] K. R. Cochran, L. Fan, D. L. DeVoe, "High-power optical microswitch based on direct fiber Actuation", Sensor and Actuators, October 2004.

[14] S. Nagaoka, "Compact latching-type single-mode-fiber switches fabricated by a fiber-micromachining technique and their practical applications", IEEE Journal of Selected Topics in Quantum Electronics, Vol. 5, No. 1. January/February 1999. 
[15] J. J. Bernstein, W.P. Taylor, J.D. Brazzle, C. J. Corcoran, G. Kirkos, J. E. Odhner, A. Pareek, M. Waelti, and M. Zai, "Electromagnetically actuated mirror arrays for use in 3-D optical switching applications", Journal of Microelectromechanical Systems, Vol. 13, No. 3. June 2004.

[16] M. N. Deeter, "High sensitivity fiber-optic magnetic field sensors based on iron garnets", IEEE Transactions on Instrumentation and Measurement, Vol. 44, No. 2. April 1995.

[17] N. Dhaubanjar. "The design and analysis of optical scanners for optical coherence tomography", Thesis, The University of Texas at Arlington, 2006.

[18] P. C. Phuyal, "Fiber optic scanner using electromagnetic actuation with different ferromagnetic materials", Thesis, The University of Texas at Arlington, 2006.

[19] P. N. Singh, P. K. Jha, "Elementary Mechanics of Solids", John and Wiley \& Sons, Inc, 1980.

[20] R. E. Rosensweig, "Ferrohydrodynamics", Cambridge University Press, 1985.

[21] J. P. Den Hartog, "Mechanical Vibrations", Dover Publications, 1985. 